\title{
Formulation of Change Management Model for Achieving Business Excellence in Large Organizations
}

\author{
THEODORA SPYROPOULOU \\ 3C Systems Thinking \\ Kifisias Ave. 268 \\ Athens, 14563 \\ GREECE \\ ANTONIOS PANAS \\ Centre for Construction Innovation \\ National Technical University of Athens \\ Athens, 15780 \\ GREECE \\ JOHN-PARIS PANTOUVAKIS \\ Centre for Construction Innovation \\ National Technical University of Athens \\ Athens, 15780 \\ GREECE
}

\begin{abstract}
This study aims to investigate how the different leadership levels can apply change management successfully in larger organisations, in order to facilitate business excellence. First, change models and leadership theories are analysed under EFQM principles, as it is selected as the framework for excellence. Then, a theoretical change management process is synthesised in alignment with leadership organisational levels. The main challenge of this research is to adequately connect theory about leading organisational change with practice. The research process is enriched by 6 semi-structured interviews in two different case studies, while the previous findings are validated through 3 structured interviews in a third case study. The analysis shows that although leaders believe that they identify the need for change, sometimes they do not, or they make sense of it too late. As such, a five-step change process model is created as the conclusion of the theoretical and case studies analyses. The value of this research is the connection between theory and practice as it tries to identify the responsible gaps for wrong or not fully successful organisational change projects. The suggested model simplifies the theory into practical steps while the success factors ensure that the enablers can support change efficiently. Further research based on the adoption of Senge's systems theory for network leadership level is recommended to organisations.
\end{abstract}

Key-Words: - Business excellence, change management, model, process

Received: April 25, 2021. Revised: October 30, 2021. Accepted: November 9, 2021. Published: November $30,2021$.

\section{Introduction}

Today's worldwide crisis can show us that western economy and business models have influenced many aspects of people's daily life [1]. There is a need for reflection and learning from both practices and theories as they need to be adopted and adapted at the same time according to society's needs [2]. In that respect, aspects related to the organisational transformation such as personal working practices have frequently been discussed. Consequently, an interesting question is how a change program can be initiated and implemented in order to be successful, as through the years it has been discussed in depth whether the huge failure rate of $70-80 \%$ in change programs exists or not [3]. In this paper the authors accept the high level of risk and difficulty in change programs as they are dynamic actions in dynamic environments [4] in an attempt to look at organisational change and try to identify the most important critical aspects of leading it successfully.

The purpose of this paper is to research how different leadership levels of larger organisations face and deal with both planned and emergent 
(sudden and unexpected) types of change. The main research question is: "How different leadership levels of larger organisations can apply change management successfully to facilitate Business Excellence?". The answers will be pursued by examining the way leadership facilitates business excellence and specifying which leadership level should act for change and when, so as for different levels of leadership to support the initiation and implementation of change.

The main challenge of this research is to adequately connect theory about leading organisational change with practice. For this reason, at the beginning, an effort for critical evaluation and holistic view of theories and models for organisational change is conducted. Subsequently, through the case studies, the competences and the way of leading in realistic work conditions are presented. Therefore, through the comparison between practice and theory, the differences between planning and implementing change, which is a part of the contribution of this research are clearly defined.

The structure of the paper is as follows: First, background information on the adopted research philosophy is presented in the next section. Subsequently, the research approach is presented accompanied with a delineation of the data collection and analysis methods. Then, the research results are presented and a discussion on emerging conclusions will conclude the study.

\section{Background}

\subsection{Research Philosophy for Organizational Change}

There are many arguments in literature about practices for organisational change, as organisations during the years have had to deal with increased levels of change that require change management as a core organisational competence [5,6]. Although, as stated before, a high failure rate in organizational change efforts has been reported, other researchers have questioned this statement based on the criticality of the evidence and the criteria according to which this high level of failure is attributed. These researchers highlight that usually the re-engineering programs are those that are more likely to fail [7], because they cannot sometimes fully satisfy the objectives of the planning phase.

Therefore, an interesting area is how the organisation should change and act when there is a demand for disseminating methods that support

quality improvement as factors like the leadership, the structure, the strategies and the culture of the company are considered essential for a successful implementation $[8,9,2]$. Moreover, literature highlights as a critical factor of change programs, people's attitudes and lack of reflection and learning [10,11,2]. This is a central necessity, among others, as there is a requirement for people who are able to understand the "why" of the change and its aspects so as to accept and support it $[10,11]$ in an attempt tocreate sustainable, long-standing, effective and successful organisations. As a result, people's psychology and competences are an essential factor for strategic and coordinated programs of change, as they usually fail due to the lack of human resources who have the necessary skills for such an implementation process $[12,13,2]$. In that view, a comparative analysis of the reviewed literature is presented in Table 1 below.

Table 1. Comparative synthesis of organisational change definitions by author

\begin{tabular}{cl}
\hline $\begin{array}{c}\text { Literature } \\
\text { source }\end{array}$ & \multicolumn{1}{c}{ Definition of change } \\
\hline$[9]$ & $\begin{array}{l}\text { (1) Benefit for the people } \\
\text { (12] Everything needs to be different }\end{array}$ \\
{$[6]$} & $\begin{array}{l}\text { (3) Observe the differences through } \\
\text { the time }\end{array}$ \\
{$[2]$} & $\begin{array}{l}\text { (4) Restructure or regenerate new } \\
\text { organizational aspects } \\
\text { (5) Ongoing instinctive responsive } \\
\text { process to survive, periods of greater } \\
\text { and lesser instability, internal/ external } \\
\text { environment } \\
\text { (6) Planned alterations to improve the } \\
\text { effectiveness }\end{array}$ \\
\hline 10
\end{tabular}
Note: In conclusion, organisational change is an ongoing process during periods of greater and lesser instability (5), consisted by planned alterations (6) and instinctive responses (5) based on empirical observations of form, quality or state over time (3) to identify everything that requires to be different (2) as to restructure or generate new organisational aspects (4) that add value to both the internal and external environments $(1,5)$.

Source: Authors' own work based on study
executed in partial fulfilment for the Degree of
Master of Science in Management for Business
Excellence at the University of Warwick




\section{Research Methodology}

\subsection{General Concepts}

Organisations, in order to survive and stay sustainable have to face the dynamic environment in which they operate and get ready for change [14, $15,16]$. However, sometimes dealing with the incremental change and/or radical business change can bring about difficulties and inefficient management practices that can create and reinforce a chaos within the organisation [17]. To deal with it and create a successful organisation there is a need for leaders who share a continuous improvement philosophy and are aware of the fact that a "deep organisational transformation is dependent on the critical mass of change initiatives" [18,14,19]. Hence, not only is it significant to have appropriate leadership style at each level, but also agreement and alignment among the different levels in order to get the buy in from all the stakeholders.

The main objectives of this research are (a) How does leadership through the years facilitate business excellence through management of change? (Research "Why?"); (b) Which leadership level should act for change and when? "Who?" \& "When?"); (c) What should each leader take into consideration during organisational change in order to deal with the business environment? ("What?");

(d) Why is a change efficient and successful? ("How?" Part 1); (e) How do the different levels of leadership support the initiation and implementation of change? ("How?" Part 2).

The first objective supports the introduction of the reader to the topic of change and aims at an indepth understanding of why a leader starts the process of change. The second objective connects change with the business environment and provides the reader with an understanding of how each leadership level can interact with the internal and/or external environment. The third objective follows to create a connection between the real world and the theory, through a comparison between the planning phase and the phase of implementation. The fourth objective supports the transfer of theoretical knowledge to fit with practice. Finally, the fifth objective delivers an evaluation of the previous four objectives. The topic of how the practices provided by theory and case studies can facilitate business excellence will be finally addressed.

In that view, decision making, business strategy, project/ risk management, leadership, emotions and people's psychology are some of the areas that influence and interact with management of change [20]. The research design is depicted in Fig. 1 below. In the initial stage of the research a literature review provides the possible augmented change model with the shortfalls in change program success. The decision for two rounds of interviews is based on the approach of focus on interviewees' feedback and contribution for redesign of the model [21]. Qualitative research has been selected as the method for analysing experience and practice against specific criteria that had been selected considering the need for generalization of the findings from the literature review [22]. The data will be compared with specific published models, frameworks and standards that are used by experts during the organisational change. Finally, they will be examined bearing in mind the assumptions and the limitations of each model that has been used.

After interviewing participants, a comparison will be drawn with the purpose of observing the difference between different styles of leadership during implementations of management of change. At this point a second comparison will be made between the conclusions reached from the literature review and the results from the aforementioned projects. In this way an attempt will be made to make a connection between the bibliography research and the realised projects and to check if the relationship between strategic design and performance is verified not to mention the optimization of the performance of leaders in the project.

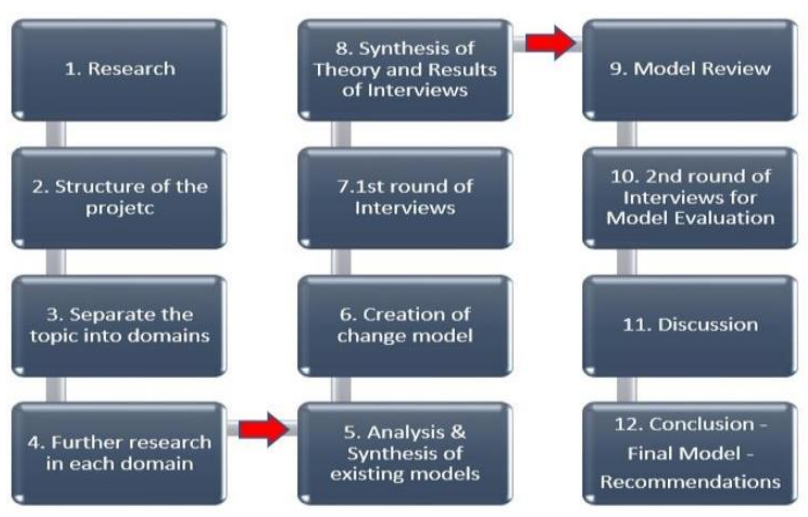

Fig. 1: Adopted research design

Source: Authors' own work based on study executed in partial fulfilment for the Degree of Master of Science in Management for Business Excellence at the University of Warwick

\subsection{Data Collection Methods}

As the research is based on case study interviews, it is very important to design a questionnaire that will provide the right questions and be communicated to the right sample of people [21,22]. This is important as having achieved a synthesis of existing 
models in literature, there is a need for generalization of the findings of the interviews, in order to achieve an effective redesign of the model. Therefore, the interviewees are selected from organisations who have already faced the challenge of change and have the experience and the knowledge to give useful feedback. Since people come from varied backgrounds and have a diverse experience, then a semi structured interview is chosen, in order to enable the interviewees to be flexible in answering based on their competences (knowledge, abilities and skills) [21,22]. These criteria are followed to ensure that different levels of leadership experience and knowledge are combined to capture the whole field of initiation and implementation of organisational change.

\section{Research Participants}

The interviews have followed the philosophy of this research and have gone from an inductive approach, as the first circle of interviews is based on the generalization of theory (six semistructured), to a deductive one, in order to draw specific logical conclusions through the second round of interviews (three structured interviews). Three companies (briefly presented below) have taken part in this research. From the first two, the HR Manager, an Operation / Change Manager and the Managing Director have been interviewed representing the three levels of leadership in an organisation.

Company 1: The Group was established in 1877 having more than 130 years of history. Since 1951 it has focused its activities to support the growing British Automotive sector. Currently, it is a Leading Provider of assembled products for the Automotive Sector, specialized in fluid and air transfer systems, structural assemblies and interior trim assemblies, with its Headquarters in Birmingham, UK. The Group has International presence, having manufacturing plants in UK and Slovakia, a Commercial Office in France and also an Indian Office, aiming to support the growing Asian Automotive sector, in its efforts to become global player in the automotive industry, employing more than 500 employees.

Company 2: The Group is a joint venture of the three European Leaders of Aerospace and Defense, being a fully integrated Defense Group in Europe and the only European one which can provide missiles and missile systems for all branches of the armed forces (air, sea, land). Currently it is a Global Group, with Subsidiaries, Joint Ventures and Sales Offices in 6 countries, France, Germany, Italy, Spain, UK and USA, employing 10.500 employees and having an annual turnover of $€ 3,1$ bn.

Company 3: The Group has more than 120 years of history and presence in the market. Currently it consists of two Divisions, Digital Security \& Information Management, with its Headquarters in Vienna, Austria. Digital Security Division has the Market Leading position in Austria Central Eastern \& Southeastern Europe, while Information Management has the Market Leading position in Southeastern Europe. The Group has 4 Production Sites, 1 in Austria, 2 in Romania and 1 in Greece, 6 Service Centers in Austria, Poland, Romania, Albania, Greece \& Turkey and 4 Sales Offices in Germany, Serbia, Croatia \& Jordan, employing about 900 employees, having an annual turnover at the level of $€ 130 \mathrm{~m}$.

\section{Results and Discussion}

Having analysed the results from the case study interviews, some questions came up as issues. It became clear that confronting these issues differed not only from organisation to organisation, but also depended on the mindsets of each individual in question and that if individuals in companies agreed about the way of addressing issues, things would be different. Therefore, the three-case studies have totally different performance, even though some individuals from different organisation totally agree on specific topics. Consequently, as highlighted in the literature review $[8,13,11,2]$, the results show that the aligned mindset in organisations is of great importance during change programs as individuals appear more determined to contribute once they feel free to express and discuss their flow of thinking, the wherefore and the why.

However, sharing the same mindset does not mean sharing the same ideas, as there is a need to challenge ideas and ways of doing things in order to achieve progress and innovation, a point made by both literature $[23,24,14,4]$ and case studies, especially Company 1 . Sharing the same mindset means that all team members and stakeholders believe in the vision and values of the organisation, putting their interests below the organisation's and agreeing about the goals they want to achieve. However, it is very difficult to achieve this aligned mindset, as was observed in all the three case studies, where the author came across challenges between the different leadership levels, among different people at the same level or between 
external and internal stakeholders. The main conclusions from each company are presented below:

Company 1: In the first case study it is clear, that people can communicate efficiently, and the core of the organisation shares mainly the same mindset, as the human resources are empowered, plays significant role in the business strategy and provides orientation. As this company follows the areas of EFQM model and has realised that in order to achieve the desired result the enablers need to be considered, this organisation needs to be careful with establishing such a strong culture, as this can lead to an organisation without space for challenging ideas or ideologies, like Disney and IBM. This is not a risk at the moment, as an interesting approach of this organisation is how they manage to control their communication process. All in all, having gone through a successful consultancy experience some years ago, this organisation has grown a framework to facilitate excellence by combining different leadership styles. Senior level has achieved a systems thinking approach [2], it has empowered the HR to look after organisation's people and has supported operations management to ensure organisation's sustainability.

Company 2: In the second organisation, the communication between the senior and the middle management is inefficient. The provided orientation is not followed because of lack of trust and acceptance. At this case there is need for discussion in order to reset the organisational culture in alignment with the vision, the mission and the values of the company. The lack of people-oriented leaders and more specifically transformational leaders is obvious and as a consequence, a chaos has been created that sets barriers between the departments and supports competition instead of collaboration. Therefore, the organisation does not work as a system [2] and the organisation separates its dynamic capability instead of using all the available sources for the facilitating organisational success. People work in the logic of the interest of their department and they ignore useful information of other organisational departments.

Company 3: The most interesting case study at this point is the third one, where although leaders at senior level have the same values, as they belong in the same culture, they do not share the same beliefs with leaders at middle management, as they come from many different cultures. Nevertheless, it is impressive that during the change projects they achieve their goals by being aligned. It has been proven through the interviews, that this is a result of all leadership levels being keen on the organisation's success and therefore they spend a lot of time on negotiations before the initiation of the project, until they ensure that all the stakeholders have agreed, and everybody is committed and engaged. Moreover, the senior management in this organisation seems to recognize the difficulties of the organisational nature in order to be adapted and aware of the demand for multi-levels leadership influence. Some educational programs and an organisational assessment according to excellence models can be recommended in order to enforce a common organisational culture and provide the sense of a common accepted goal for the future of the whole group.

Therefore, the main and most important question seems to be "How to make change an irrevocable and integral part of the organisational system". The significance of this question comes from the fact that although all the three case studies appear to be progressive, parts of them are indeed static. The first organisation is static in terms of the fact that everything in order to proceed needs to get the approval of the Managing Director. The second organisation is static because senior management cannot be adapted to the continuously changing environment. The third organisation is static in part of communication and operational processes because leaders need to change them into more automatic, as they spend a lot of time on them. This stability in all organisations seems to result from three main factors. The first may be due to the leaders' inability to adapt their style and way of working on their team members and the situation. The second could be due to the leaders' difficulty to gain the people's acceptance and commitment to the change program. The third one is that leaders spend their time on tasks they should not.

\section{Proposed Change Management Model}

Having completed the study and based on the combination of the theory with the analysis of the results, the author believes that Senge's model at "Dance of change" [2] presents a very interesting life cycle of an organisational strategic change process. Moreover, during the second round of interviews it is verified that "develop future leaders" and lack of competences are two of the most important future challenges. Along these axes, the Work Breakdown Structure of the proposed change management model is presented in Fig 2. 
Table 2 presents indicatively three critical success factors (CSF) that occurred as results of the analysis, for each one of the five proposed phases of change: Start (recognize, identify, align), Plan, Initiate, Implement, End (evaluate, learn).

During the interviews the question of "Who drives the change?" was addressed. It was concluded by the majority that the leaders need to inspire people to make sense of the need for change and to take ownership of it. Nevertheless, a small minority supported that the leader was responsible for all aspects of managing people to make the change. These results were the expected ones in times of planned or emergent change depending on the time restrictions. However, although this was true to a small extent it became clear that how people work depends largely on organisational culture.

Table 2. Indicative Critical Success Factors (CSF) of the proposed change management model

\begin{tabular}{|c|c|}
\hline $\begin{array}{l}\text { Model } \\
\text { phase }\end{array}$ & Critical success factors (CSF) \\
\hline 1.Start & $\begin{array}{l}\text { Ensure company's future is above } \\
\text { individuals' interests; } \\
\text { Ensure everybody from the board, } \\
\text { first line management and } \\
\text { consultants are willing to shape the } \\
\text { vision and strategy according to the } \\
\text { organisation's values; } \\
\text { Keep the balance between too much } \\
\text { discussion Vs act fast }\end{array}$ \\
\hline 2.Plan & $\begin{array}{l}\text { Ensure that team members fit for the } \\
\text { purpose; } \\
\text { Define project monitoring in } \\
\text { different levels according to relevant } \\
\text { KPIs; } \\
\text { Ensure conflicts handling through } \\
\text { escalation processes }\end{array}$ \\
\hline 3.Initiate & $\begin{array}{l}\text { Ensure that all leadership levels } \\
\text { provide appropriate orientation; } \\
\text { Ensure people understand the } \\
\text { "why"; } \\
\text { Ensure appropriate and continuous } \\
\text { communication at every level }\end{array}$ \\
\hline 4.Implement & $\begin{array}{l}\text { Keep aligned organisation's and } \\
\text { individuals' goals; } \\
\text { Empower early adopters; } \\
\text { Share the winning mentality }\end{array}$ \\
\hline 5.End & $\begin{array}{l}\text { Reflect on leadership style; } \\
\text { Discuss gaps between initiation and } \\
\text { implementation phases with project } \\
\text { team; }\end{array}$ \\
\hline
\end{tabular}

Reflect on coaching effectiveness and methods

Source: Authors' own work based on study executed in partial fulfilment for the Degree of Master of Science in Management for Business Excellence at the University of Warwick

If people have learnt to work as agents under complex leadership styles, even under time constraints, they can adapt and combine a more autocratic way of delegating roles and responsibilities with a transformational way of enabling people to deal with the tasks themselves. On the contrary, if the leaders are less open and transparent, even if time is plentiful and prefer to hand out specific instructions according to the way of working, then employees are not allowed to take any initiatives, but rather to act as robots.

So, it comes back to the question of what should come first? The urgency as [10] suggests at his eight steps or the need to make sense and identify the need for change according to [25]? It seems that leaders who are able to make sense and identify the need for change can create a vision, that keeps everyone aware of this in the company. However, in order to achieve a high level of compliance within the organisation, sometimes vision is not enough as the planning phase can lead to a loss of time management control. Consequently, an appropriate amount of urgency that works as a catalyst and not as an obstacle is essential (e.g. through coaching and mentoring). This can be achieved through coaching and mentoring, that provide a focus on Individuals as unique parts of a system and not the system as a combination of individuals. The latter contributes to the recognition of the individual as an autonomous agent within the company, which is essential in the formation of a middle management which can be central to saving the day when senior management fails to do so. To sum up, individual competences are an essential factor to turn people into the key success factor of a project and dealing with lack of them can be proven the catalyst for a successful interdisciplinary collaborative project.

\section{Conclusion}

\subsection{Research Limitations}

As different people have a different perception of each word of the same language, there is a limitation in communicating, understanding and analyzing the information given. In this research there is an attempt to address the "why" and the 
"what" of change projects. As the "how" depends on much more detail of the nature of the change projects, limited tools have been discussed and suggested. Moreover, studying organisational change demands an ability to translate theory into action. However, the author's limited work experience on change programs results in a limitation in the in-depth comprehension of the initiation and implementation of change. Additionally, as each different case study in organisational change adds value to this concept, the examination of three case studies and limited aspects of the theory do not establish the outcome of this research as a rational model. Nonetheless though, the research is a significant indicator of change management drivers that can be used by

\subsection{Research Contribution}

Considering that there is a high level of failure in change programs, through the connection between the theory and the practice, this research can support reflection and learning. More specifically, through the matching between the theory and the implemented practices for change, readers can reflect on what they have done in the past, what they are doing now and how they will address the future challenges based on these reflections.

A critical part of this study is that people can read about organisational change not just as a need, but as a search for excellence. This enables readers to understand that change is necessary for organisations not only in order to survive but also to shape the future, which can be seen as a point of

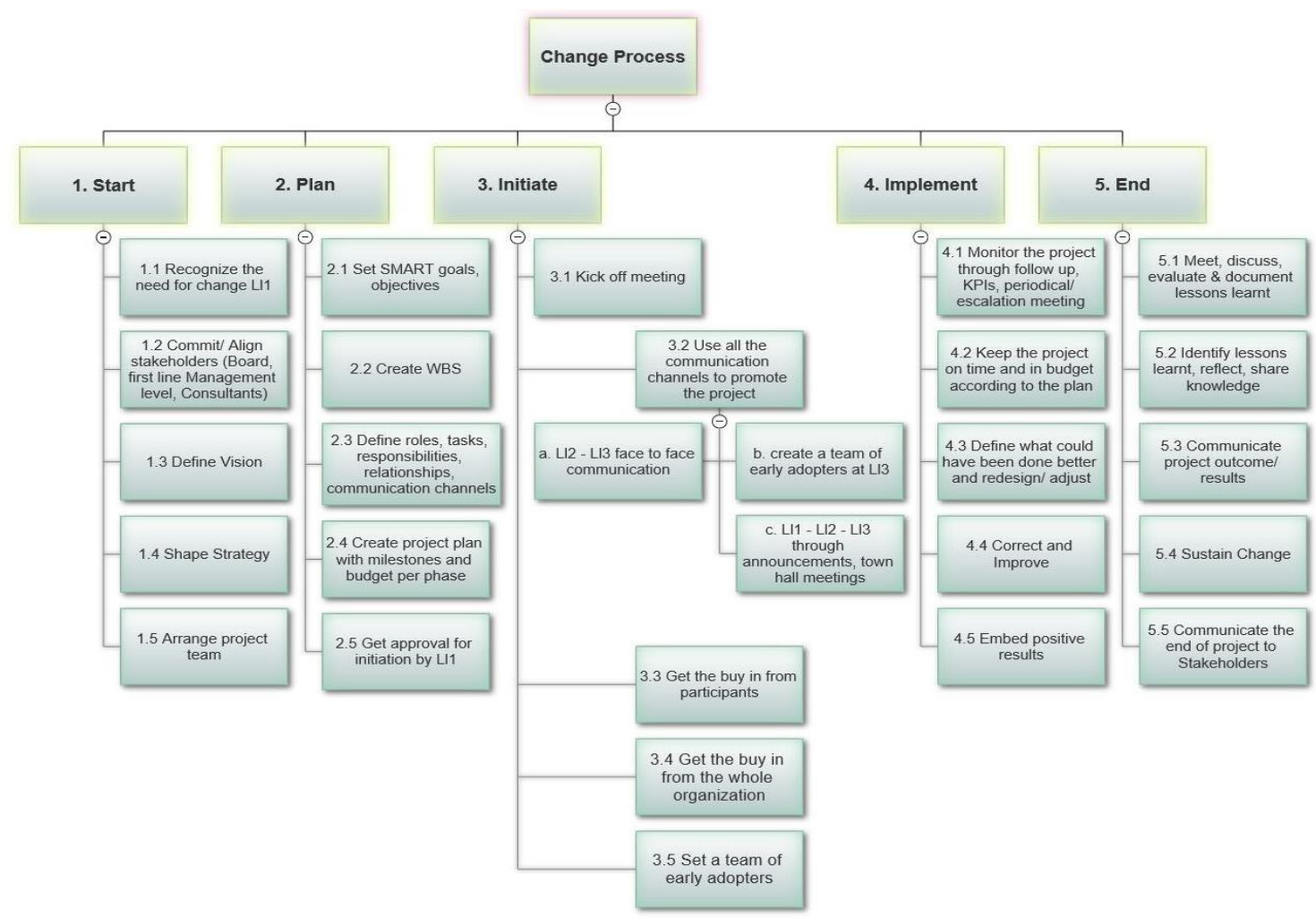

Fig. 2: Final WBS of the proposed change management model

Source: Authors' own work based on study executed in partial fulfilment for the Degree of Master of Science in Management for Business Excellence at the University of Warwick

both managerial and senior / executive personnel under the prism of the exact organizational characteristics, philosophy and culture. departure from alternative studies presented in published literature. More specifically, to reduce the negative influences of a crisis or a failure during a change program within the organisation, leaders need to have the ability to zoom out, observe and 
recognize the criticality of the situation and its needs. In that respect, it would be helpful for the reader to adopt this technique of zoom out and reflection when studying the research, in order to be benefited at the highest level.

\subsection{Future Research Directions}

Studying the organisational change concept, it becomes evident that this is a well-known concept which all the interviewees of the case studies were in theory well informed about. However, a difficulty in the implementation of this theory has been observed. It seems that when looking carefully to translate theory into practice in terms of techniques, tools and processes, a gap is created in educating people to become strategic agents, who will not only apply best practices but also create invaluable business models. This comes to enforce Porter's criticism of the limitation of his model "five forces" in terms of its ability to deal with today's dynamic environment. In view of this, two main obstacles appear to hinder the successful application of change programs. First, the misconception that huge amounts of data and details support communication and, secondly, the lack of competences which weakens the ability to face and deal with leadership challenges. Additionally, the conflict of ideology between the contemporary generation and the upcoming millenniums also plays a major role. As a general conclusion, the root cause lies in the deficiency of critical thinking. Finally, the creation of an environment where complex leadership develops autonomous agents and supports organisational change in search of business excellence is of paramount importance. Based on these, and considering the results of future challenges, demands and drivers, the authors conclude to suggest the development of a Strategy \& Change department for large organisations. This will support them by analyzing the business environment, identifying opportunities and areas for improvement, designing new business models and developing a "change-friendly" environment. Moreover, further scientific research is suggested in the area of connecting the theory of organisational change to practice and more specifically, how to transform organisational change into parts of day to day management processes.
References:

[1] Coombs, W. \& Laufer, D., Global crisis management - Current research and future directions, Journal of International Management, Vol. 24, No. 3, 2018, pp. 133162.

[2] Senge, P., The dance of change, Nicholas Brealey, 1999.

[3] Daft, R. L. \& Marcic, D., Understanding management, Nelson Education, 2016.

[4] Geer-Frazier, B., Complexity leadership generates innovation, learning and adaptation of the organization, Emergence: Complexity \& Organization, Vol. 16, No. 3, 2014, pp. 105116.

[5] Burnes, B., Complexity theories and organizational change, International Journal of Management Reviews, Vol. 7, No. 2, 2005, pp. 73-90.

[6] Dawson, P., Reshaping change: a Processual Perspective, London Routlege, 2003.

[7] Hammer, M. \& Stanton, S. A., The Reengineering Revolution: A handbook, Hammer and Co, 1995.

[8] Johnson, G., Scholes, K. \& Whittington, R., Exploring corporate strategy, Pearson Mexico, 2011.

[9] Remme, J., Jones, S., Heijden, B. \& Bono, S., Leadership, Change and Responsibility, Meyer and Meyer Aachen, 2008.

[10] Kotter, J. P., Leading change, Harvard business press, 1996.

[11] Pfeffer, J., Competitive advantage through people: Unleashing the power of the work force, Harvard Business School Press, 1996.

[12] Burnes, B. \& Jackson, P., Success and failure in organizational change: an exploration of the role of values, Journal of Change Management, Vol. 11, No. 2, 2011, pp. 133162.

[13] Page, T., Diary of a change agent, Gower Publishing, 1996.

[14] EFQM, EFQM Excellence Model: Excellent Organisations achieve and sustain outstanding levels of performance that meet or exceed the expectations of all their stakeholders, EFQM Publications Brussels, 2012.

[15] Sumantri, S., H., Thamrin, S., Apriyanto, I. N. P., Suhardono, E., Rudiawan, B. \& Susanto, A. D., SWOT and AHP Analysis in Determining the Strategy of Product, Marketing Excellence in Companies, International journal of circuits, systems and signal processing, Vol. 14, 2020, pp. 110-115. 
[16] Gashi, E. \& Sadiku, H., Quality Management for Road Network Organizations, WSEAS Transactions on Environment and Development, Vol. 16, 2020, pp. 237-242.

[17] Moreno-Menéndez,, A., M., Arzubiaga, U., Díaz-Moriana, V. \& Casillas, J. C., The impact of a crisis on entrepreneurial orientation of family firms: The role of organisational decline and generational change, International Small Business Journal: Researching Entrepreneurship, Published online, 2021 (doi: doi/abs/10.1177/02662426211036694)

[18] Deming, W. E., The New Economics for Industry, Government, Education, The MIT Press, 2018.

[19] Hernandez, E. \& Menon, A., Corporate Strategy and Network Change, Academy of Management Review, Vol. 46, No. 1, 2021 (https://doi.org/10.5465/amr.2018.0013).

[20] Kotter, J. \& Cohen, D., The heart of change, Harvard Business School Press, 2002.

[21] Gillham, B., Developing a questionnaire, Bloomsbury London, 2015.

[22] Yin, R., Case study research, Sage Publications, 2003.

[23] Bel, R., Leadership and innovation: Learning from the best, Global Business and Organisational Excellence, Vol. 29, No. 2, 2010, pp. 47-60.

[24] Panupaisal, N., Factor in Organizational Learning to Promote Learning which Affects to Support's Levels of Learning in Naresuan University, Journal of Social Sciences Naresuan University, Vol. 17, No. 1, 2021, pp. 71-94 (https://doi.org/10.14456/jssnu.2021.3).

[25] Kanter, R. M., Rosabeth Moss Kanter on the frontiers of management, Harvard Business Press, 2003.

\section{Contribution of Individual Authors to the Creation of a Scientific Article (Ghostwriting Policy)}

Theodora Spyropoulou carried out the conceptualization of the research design and data collection. Antonios Panas coordinated the writing and visualization of the original manuscript. JohnParis Pantouvakis contributed in reviewing and editing the manuscript.

\section{Sources of Funding for Research Presented in a Scientific Article or Scientific Article Itself}

The publication of the article was financed in the framework of the contract no. DNK/SN/465770/2020 by the Ministry of Science and Higher Education within the "Excellent Science" programme.

\section{Creative Commons Attribution License 4.0 (Attribution 4.0 International, CC BY 4.0)} This article is published under the terms of the Creative Commons Attribution License 4.0 https://creativecommons.org/licenses/by/4.0/deed.e $\underline{\mathrm{n} U S}$ 